\title{
Development of High Power LED Driver Using LTSpice Software
}

\author{
${ }^{1}$ Muhammad Ikram Mohd Rashid, ${ }^{2}$ Suliana Ab Ghani, ${ }^{3}$ Mohamad Fakhrudin Sulaiman Mustahim \\ Sustainable Energy \& Power Electronics Research Group(SuPER) \\ Faculty of Electrical and Electronics Engineering, Universiti Malaysia Pahang, Pahang, Malaysia \\ 1'mikram@ump.edu.my, ${ }^{2}$ suliana@ump.edu.my, ${ }^{3}$ mfakhru86@yahoo.com
}

\begin{abstract}
LED technology has been used widely in various applications due to its advantage in term of functionality, high efficiency, low cost, small size and high reliability. In order to improve LED performance and prolong LED's life, High Power LED driver is been developed. LED driver is used to control output voltage by using current mode controlled method. This development of LED driver can increase the LED operation efficiency, provide high voltage protection, decreases the driver size and lastly make possible of user friendly installation. Voltage source is step up by using boost converter as main circuit. In control circuit, current mode controlled is used to regulate output characteristic of High Power LED. LTC 3783 is used as PWM controller to drive the gate and provide pulse signal to the MOSFET. This driver is designed to operate load that consists of 6 units LED each rating of 5 Watt connected in series. Theoretical calculation is made to obtain component specification. The LTspice software is used to simulate the driver circuit by using calculated parameters before move on to hardware implementation. Eagle software is used to design the Printed Circuit Board (PCB). Then, all components are mounted on the PCB which is made of FR4 material. The hardware built is tested experimentally and the output waveform is recorded.
\end{abstract}

\section{INTRODUCTION}

Currently, the advancement in the high-power LED are increasingly finding new application in emergency light, street lighting, traffic lights, automobiles, cars, flashlight and general purpose lighting. Because of their superior longevity, low maintenance requirement, improved luminance, there is no mercury inside the devices. Therefore, they perform an extremely long operating life [1].

Typical LED control circuits are designed around a buck, boost or flyback topology, and they are used to generate a constant DC current through a string of a given number of LEDs. Each of these topologies has advantages and disadvantages depending on the input voltage range, the number of LEDs being driven in series, the number of parallel LED strings, the LED output current, if isolation is required, if dimming is required, efficiency, size and cost. For this reason, many circuit variations exist to satisfy the many different LED applications. The new circuit is a resonant mode circuit that has been slightly modified from dimming fluorescent applications. It is for non-isolated, off-line applications, and can drive one or many LEDs in series, can be easily scaled for different LED current levels, and utilizes soft-switching for good efficiency [2].

LED lighting system consists of three major parts. The three major parts is power source, lighting controller, and LEDs module. LED's in series or parallel connection must be driven with a source of constant current. Most of LED's have a specified current level that will achieve the maximum brightness for high efficient level.This brings about the need for high-power LED driver that can deliver and regulate LED current in a power-efficient manner. Normally for high power LED module will produce heat after several times. It is difficult to control LED due to its electrical characteristics of nonlinearity and temperature sensitivity. This project is about constructing a controller circuit by using a current mode PWM controller as driver for LED module [3].

Power LEDs are current controlled devices rather than voltage, since the output luminous flux is determined by the forward current running through them. So, the current regulators are to be used. Linear regulator is a conventional switching in the lighting system. Linear regulator usually work quite well in the lighting system where the forward current is kept at a low level, whereas the efficiency drops as forward current rises. Besides, the load voltage must be lower than the supply voltage; otherwise the LED lamp does not work. Switching topologies have an extremely good performance operating LED lamps at high current levels while keeping at low level the losses in the converter, avoiding in this way the drop in efficiency that happens when linear regulators are operated at high current. There are three basic types of dc-dc converter (switching converter): step-down converter (Buck Converter), step-up converter (Boost Converter) and step-updown converter (Buck Boost Converter). In this project, boost converter is focused. Pulse width modulation (PWM) technique is to be used to control the density of the LED light in the switching converters [4].

Power LEDs are current controlled devices rather than voltage. The luminous flux is determined by the forward current. As a result, the power LEDs requires a controlled output current. The conventional current control in the LED 
driver is using the linear regulator. In the linear regulator, bipolar junction transistor BJT will be used with the operation in active region. The load current (collector current) is controlled by the value of the base current. In order to produce a large load current, a Darlington pair BJT is used. However, the power dissipation of the BJT is very big due to high current flow. The BJT may be burnt [5].

Due to the high power loss in the BJT, it is replaced by an alternative current controller, called PWM controller. The main advantage of the PWM controller is it has better efficiency and can be widely applied to LED driver circuit. PWM controller is a control device which can be used as Voltage mode control (VMC) and Current mode control (CMC). In VMC, the control loop is set up so that the output voltage is compared to a reference voltage by an error amplifier. The output of the error amplifier equals the error. In other words, the amount of feedback voltage is away from the reference voltage. This error voltage is then compared to a wheeling saw-tooth voltage, and a PWM comparator sets the duty cycle for the power switch. The advantages of this topology are that the control loop can be made relatively fast and there is no minimum on time required. However, the disadvantage of this mode is any change in line or load must be first sensed as an output change and then corrected by the feedback loop. Normally it will take a period of time for doing the correction and hence this means slow response. Figure 1 shows the graphical presentation of the voltage mode control.

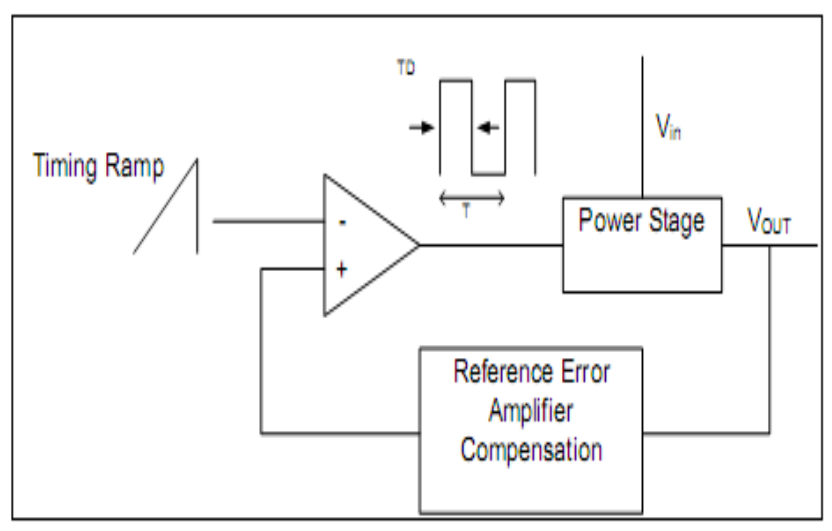

Fig. 1 Voltage mode control. [6]

In $\mathrm{CMC}$, it is implemented through two control loops: inner loop and outer loop.

Outer loop monitors the converter's output voltage. It measures the output voltage and provides an error signal to the inner loop. The inner loop monitors the inductor current information and creates the voltage-controlled current source. Inner loop compares the error signal and an analog of the inductor current to decide when to turn off the switch. The effect is to change the pulse width. The pulse width is a function of the inductor current rather than a function of the error signal. Figure 2 shows the graphical presentation of the current mode control.

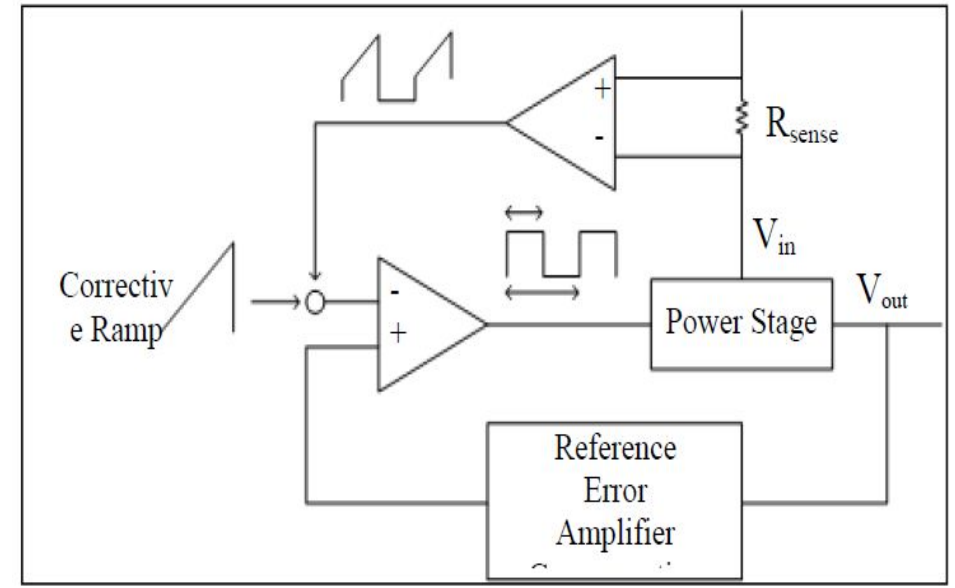

Fig. 2 current mode controls. [7]

The operation of the current mode controller has advantages over a voltage mode controller. The first is that the inductor current is a direct function of the error voltage, so for small signal analysis the inductor can be replaced by a voltage controlled current source. This removes one order from the transfer function. The control loop is easier to compensate than a voltage mode circuit. Another advantage is that input line voltage changes are removed from the compensation problem. The peak current through the inductor is a function of the voltage across current to rise to the required value and for the comparator to shut off the switch. [8]

There is one problem faced by the current mode PWM controller. The inner current loop is unconditionally stable as long as the duty cycle is below 50\%. However, the output will diverge from stable control when the inner loop is perturbed by noise or transient as the duty cycle is larger than $50 \%$. A current mode controller can be stabilized to maintain control by adding slope compensation. The slope compensation is usually accomplished by feeding some of the voltage from the oscillator capacitor into either current sense amplifier is the error amplifier. It changes the current trip from a constant voltage to a saw-tooth waveform at the switch frequency.

\section{Design Methodology}

\section{A. Software}

To analyze the circuit design, simulation part is a first step must complete before can proceed to develop hardware. The simulation should be done to ensure all selected component parameter is correct. If the simulation result can't achieve the objective, some modification can do without any wasting cost. The part is also important because if any failure of the circuit operation occurs, the cause of the failure can be traced by this simulation. If the prototype is developed without doing the simulation, any failure of the circuit will cause the damage on the components. So, the budget of the project needed to buy the new components can be minimized.

For this project, the software that has been used:

a) LTspice software - for simulation. 
b) Easily Applicable Graphical Layout Editor Software (EAGLE) - for design PCB layout.

\section{B. LT Spice Simulation}

Design the power stage and controller by using the LTspice simulation in order to obtain the parameter that is suitable for implementing the hardware. The figure 3 below shows the complete circuit of boost converter with current mode control. A set of fundamental power electronics equations was use to obtain the desired parameters. The values obtain would be passed out to other circuits to be analyzed. The parameter for component obtained from simulation can used to implement into hardware component. So it will be easier to design the real circuit. The nearly value of component can be get by will display the waveform and show the performance of circuit based on the value desire for design circuit. At this time, the input voltage and output voltage can be determined.

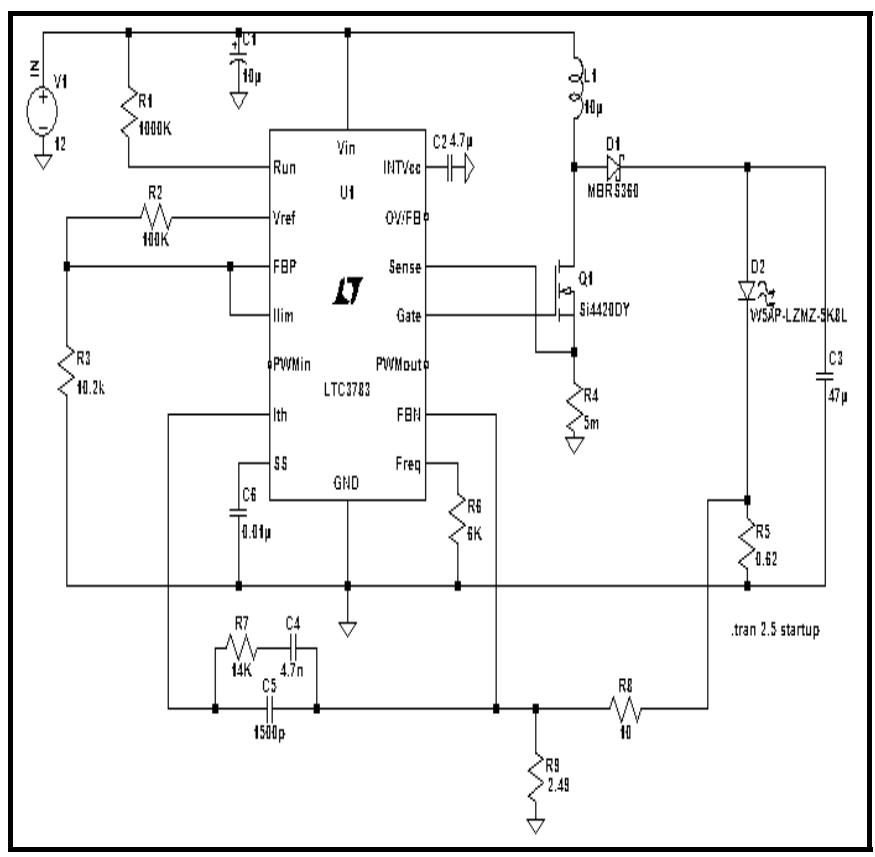

Fig. 3. Power Stage and Controller circuit

\section{Design \& Parameters Specification}

For hardware implementation part, the value of all components parameter must be design first. The value of the component will get by using all fundamental power electronics formula. The specifications design for boost converter for this project is shown in the Table 1.

TABLE I

Boost converter design specification

\begin{tabular}{|c|c|c|}
\hline DESCRIPTION & PARAMETERS & VALUE \\
\hline $\begin{array}{l}\text { Input } \quad \text { Voltage } \\
\text { (Vin) }\end{array}$ & Vin & $\begin{array}{l}12 \mathrm{~V} ; \text { nominal } \\
12 \mathrm{~V}\end{array}$ \\
\hline Output Voltage & Vout & $22 \mathrm{~V}$ \\
\hline
\end{tabular}

\begin{tabular}{|l|l|l|}
\hline Output Current & Iout & $1 \mathrm{~A}$ \\
\hline $\begin{array}{l}\text { Switching } \\
\text { Frequency }\end{array}$ & Fs & $1 \mathrm{MHz}$ \\
\hline
\end{tabular}

TABLE II

List Of Parameters ( Power Stage )

\begin{tabular}{|l|l|}
\hline COMPONENT & VALUE \\
\hline Inductor,L1 & $10 \mu \mathrm{H}$ \\
\hline Resistor,R1 & $1 \mathrm{M} \Omega$ \\
\hline Resistor,R3 & $0.65 \Omega$ \\
\hline Capacitor,C1 & $10 \mu \mathrm{F}$ \\
\hline Capacitor,C3 & $47 \mu \mathrm{F}$ \\
\hline Power Mosfet & $\mathrm{S} 12308 \mathrm{BDS}$ \\
\hline Diode & $2.0 \mathrm{~A}$ \\
\hline
\end{tabular}

TABLE III:

List Of Parameters (Control Circuit)

\begin{tabular}{|l|l|}
\hline COMPONENT & VALUE \\
\hline Capacitor,C4 & $4.7 \mathrm{nF}$ \\
\hline Capacitor,C5 & $100 \mathrm{pF}$ \\
\hline Capacitor,C6 & $0.01 \mu \mathrm{F}$ \\
\hline Resistor,R2 & $0.05 \Omega$ \\
\hline Resistor,R4 & $6.04 \mathrm{k} \Omega$ \\
\hline Resistor,R5 & $10 \Omega$ \\
\hline Resistor,R6 & $2.49 \Omega$ \\
\hline Resistor,R7 & $14 \mathrm{k} \Omega$ \\
\hline Resistor,R8 & $10.2 \mathrm{k} \Omega$ \\
\hline Resistor,R9 & $100 \mathrm{k} \Omega$ \\
\hline PWM IC & $\mathrm{LTC} 3783$ \\
\hline
\end{tabular}

\section{Hardware Implimentation}

Printed Circuit Board (PCB) is constructing for this project. The figure 4 is show the complete PCB layout circuit by using Eagle software. Then the complete PCB board is shown in figure 5 after done do all process. There are several procedures to produce the PCB which is listed below:

a) Construct and design PCB layout using Easily Applicable Graphical Layout Editor Software (EAGLE).

b) The arrangement and pad size has to be made carefully in order to prevent the short circuit at the board.

c) The complete design for circuit is converting to Gerber file.

d) LPKF machine plotter is use to making the complete circuit board. 


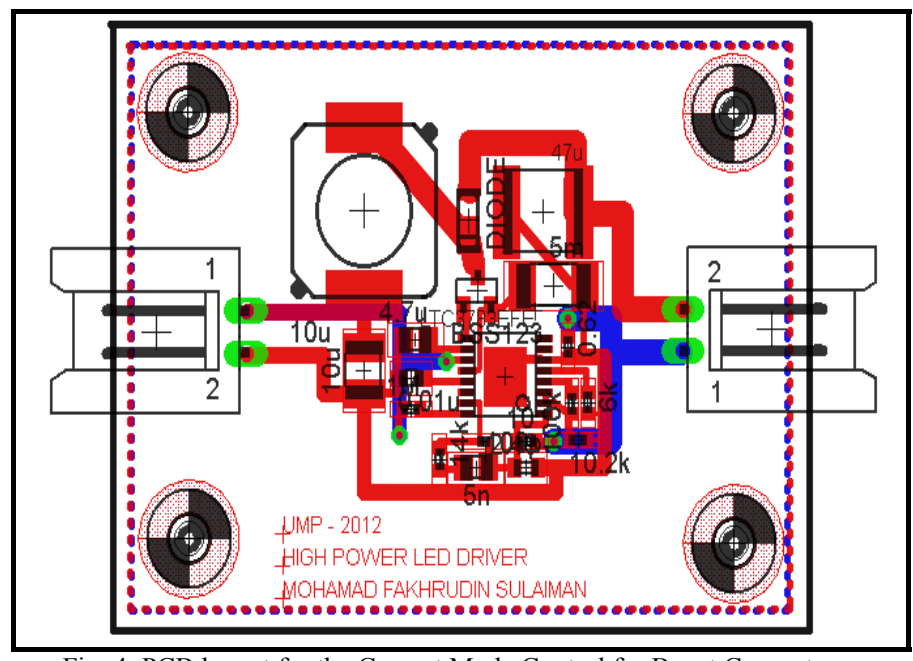

Fig. 4. PCB layout for the Current Mode Control for Boost Converter

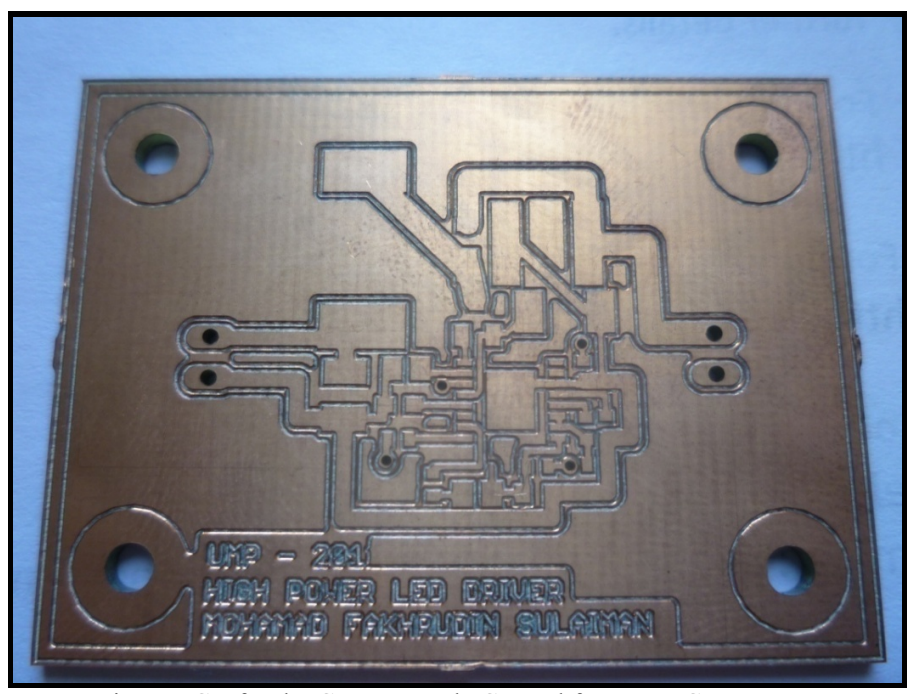

Fig. 5. PCB for the Current Mode Control for Boost Converter

\section{A. Simulation}

III. RESUlts AND Discussion

By fixed $12 \mathrm{~V}$ as input supply, the output voltage will get $20.6 \mathrm{~V}$ and the current $920 \mathrm{~mA}$. This output rating is suitable to drive LED string because this value is under typical rating for each High Power LED. The PWM IC will represent the waveform of the inductor current and gate voltage in the same time. The duty cycle is 0.01 . The switching frequency use is $1 \mathrm{MHz}$. Figure 6. shown the Input voltage and output voltage. Figure 7 below has shown the waveform of output current. The Figure 8 has shown the waveform of inductor current (current sense) and Figure 9 shown the waveform at gate MOSFET (duty cycle).

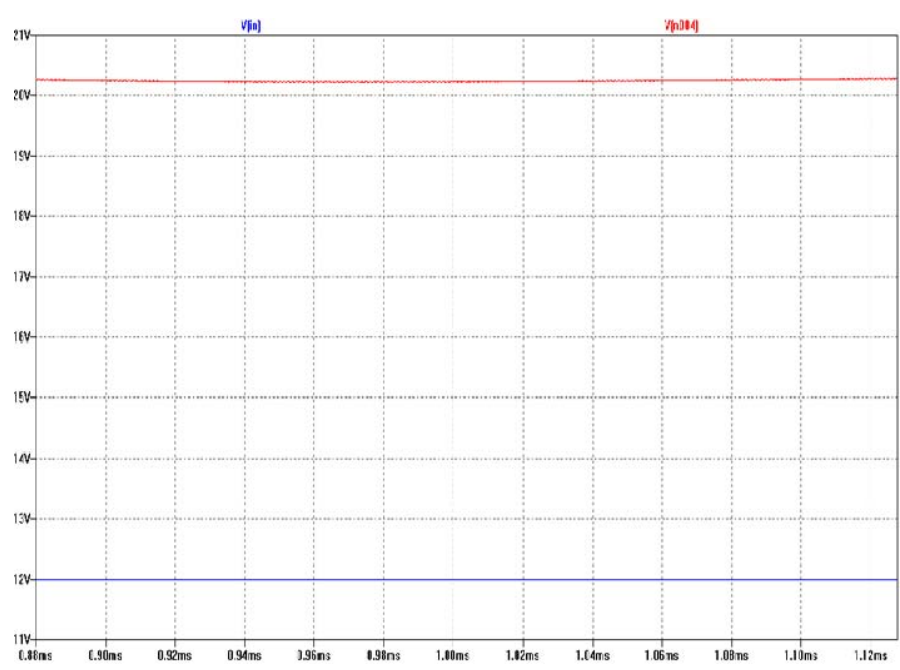

Fig. 6 Waveform of Input voltage and output voltage

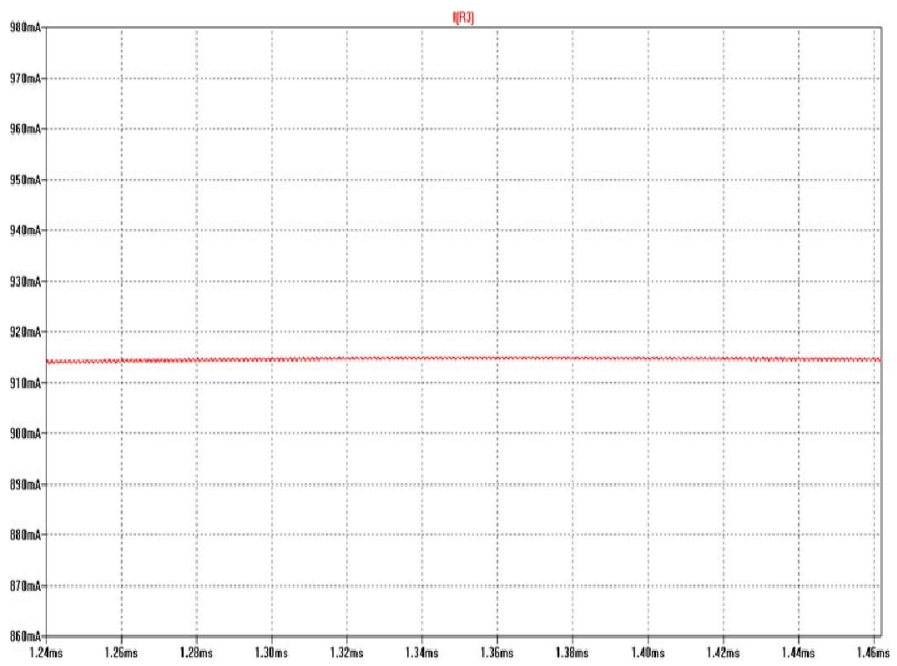

Fig. 7 Waveform of output current

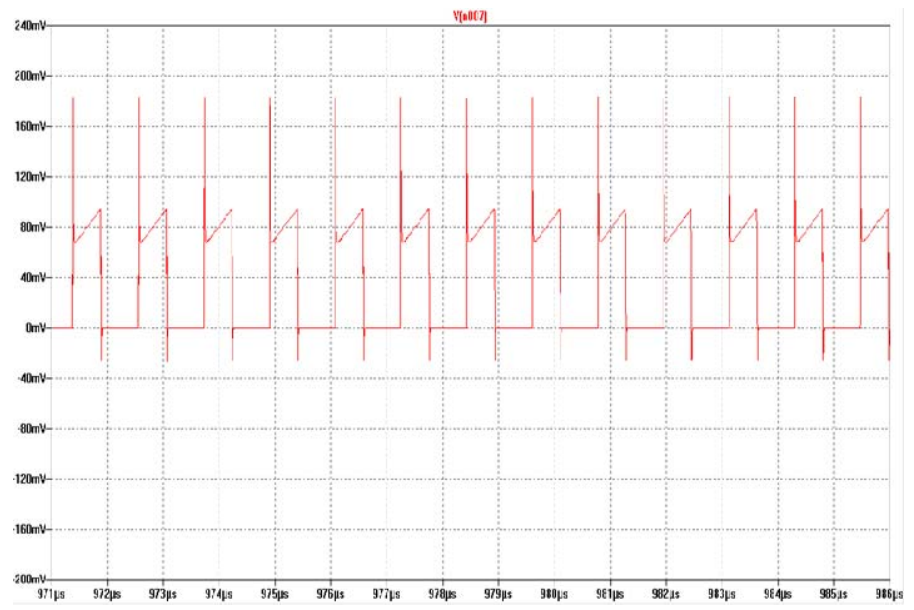

Fig. 8 Waveform of Current Sense 


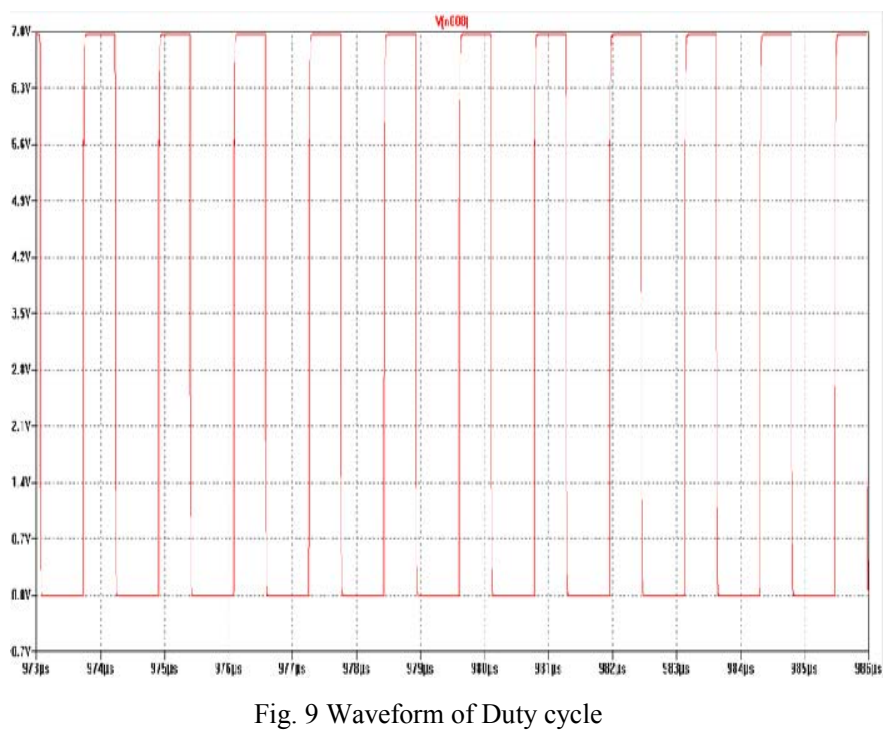

Figure 10 show that the result of PWM waveform for boost converter. The duty cycle of 0.01 show that this PWM waveform. The error amplifier generates is comparing an output voltage and the voltage at voltage reference to controlling the output voltage. It generated from the internal oscillator by connecting the timing resistor at frequency pin. At this time, the actual frequency $1 \mathrm{MHz}$ also can be proof. It will produce the PWM output which is a square wave (Figure 9 and 10).

\section{B. Experiment}

Oscillator is use by doing analysis after done the hardware implementation. Firstly, the analysis had done on the PWM control IC which is use the LTC3783 to get square waveform. This waveform are represent the gate driver signal to drive get MOSFET. Lastly, analysis at power stage is done to get the output voltage and current to drive the LED string as a load. The figure below showed the result get in hardware implementation.

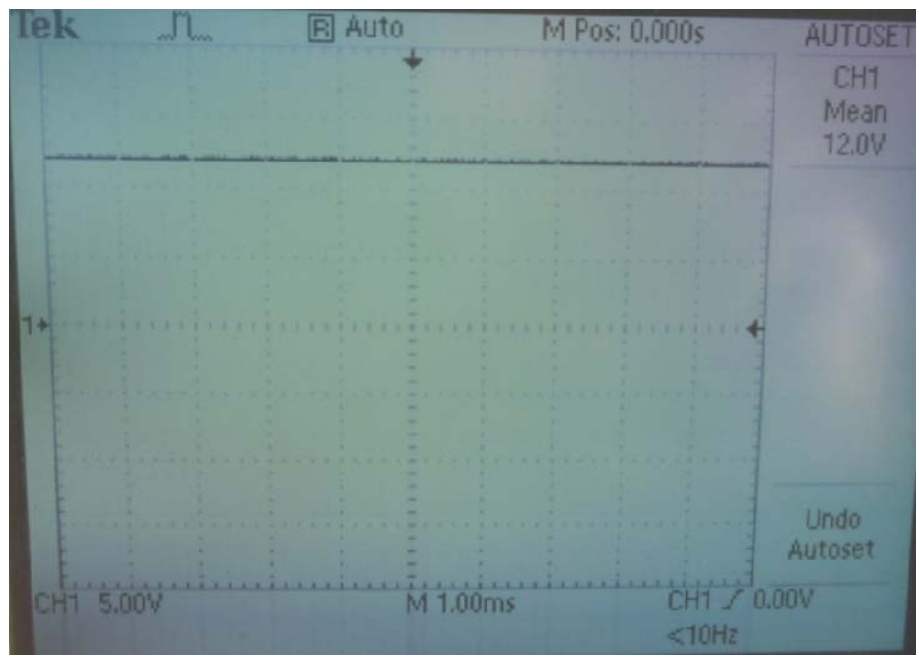

Fig. 10. Input voltage to the drive driver circuit

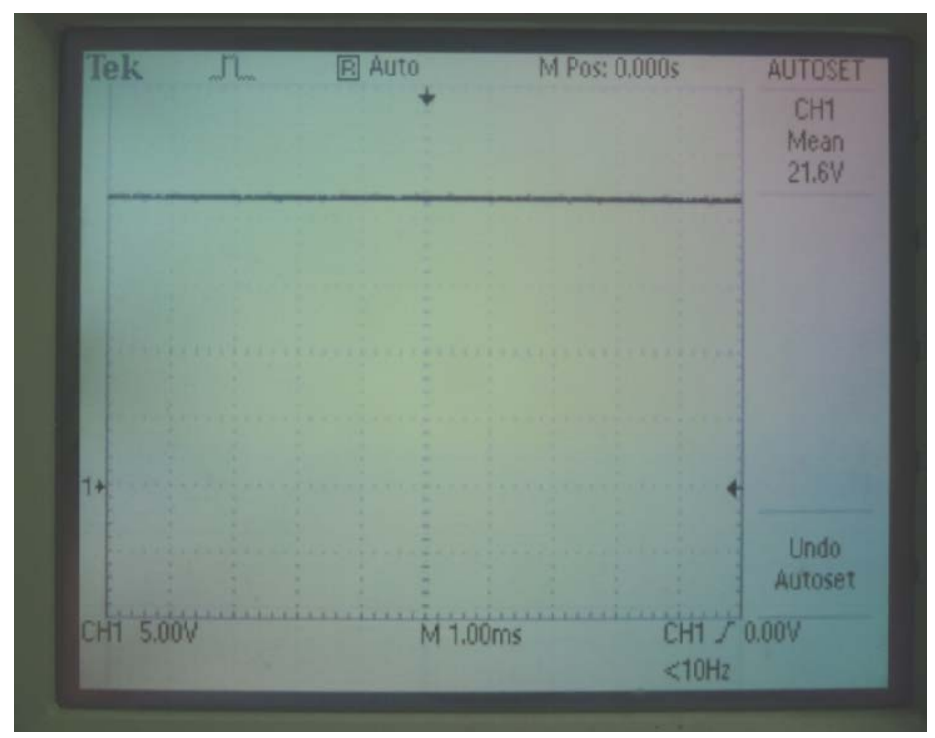

Fig. 11. Output voltage to the drive the LED string
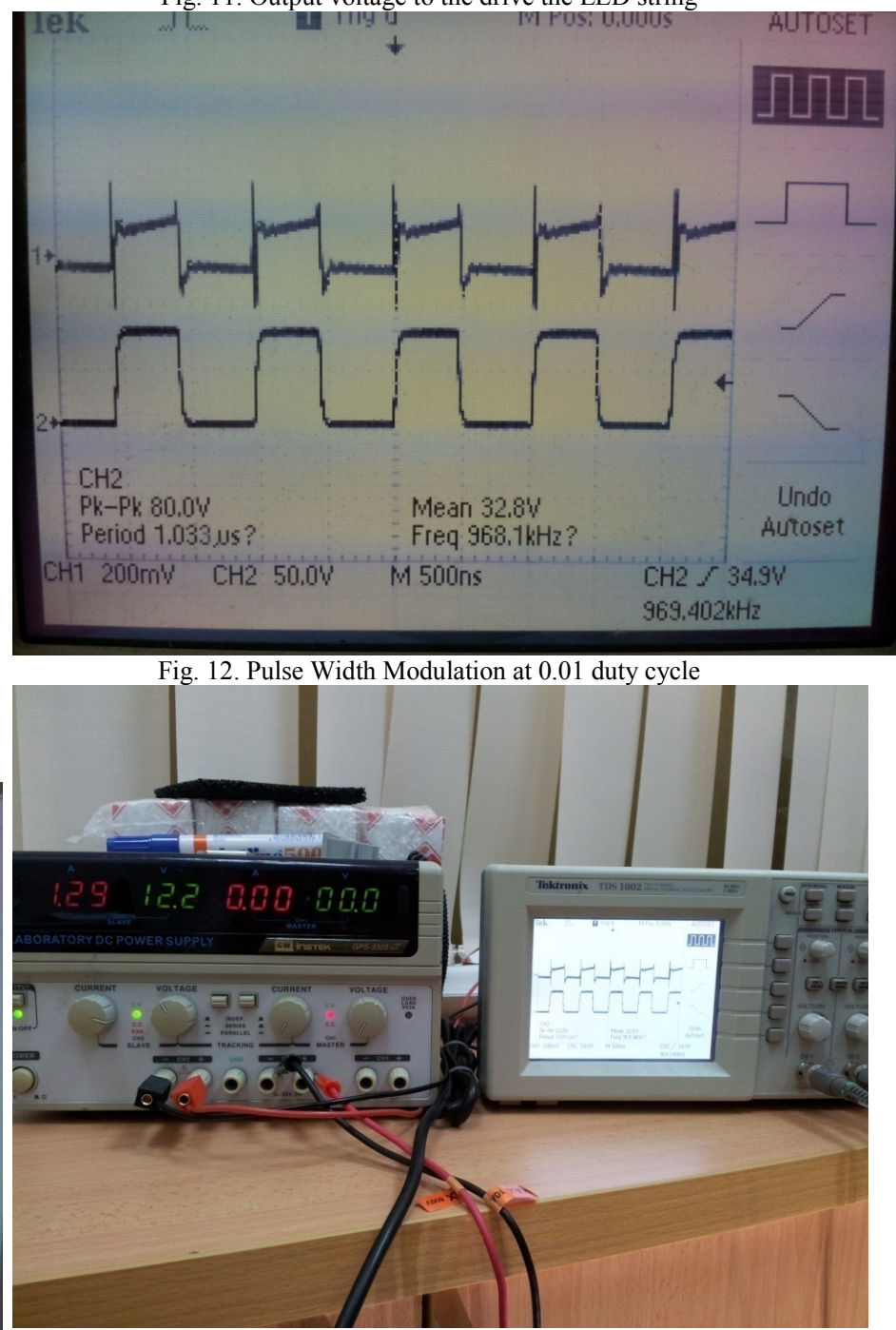

Fig. 13. Supply $12 \mathrm{~V}$ to the PWM Pulse Width Modulation 


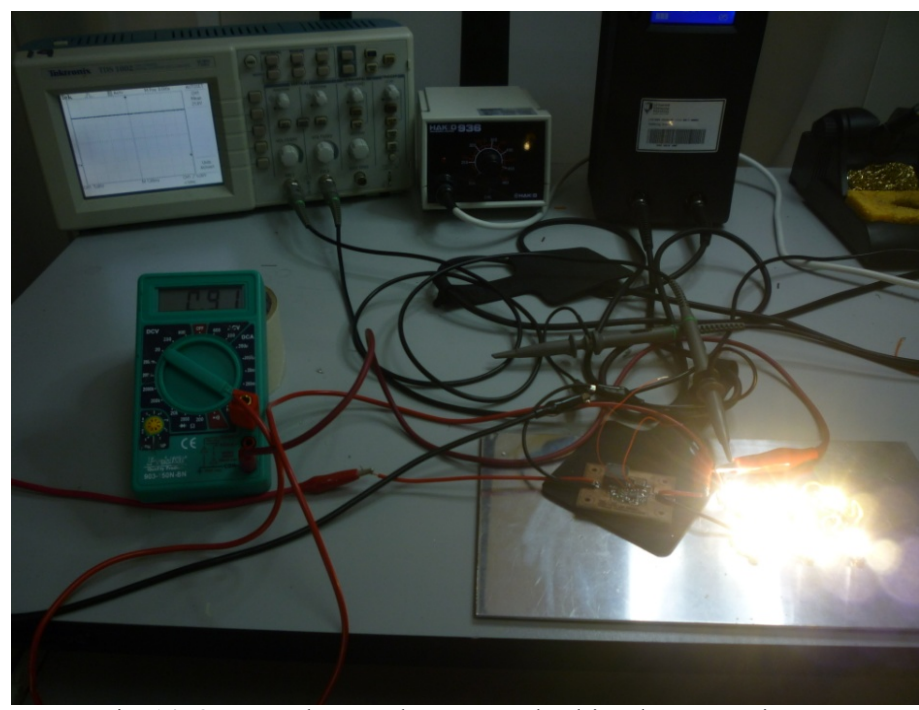

Fig. 14. Output voltage and current to the drive the LED string

Figure 12 show that the result of PWM waveform for boost converter. The duty cycle of 0.01 show that this PWM waveform. The error amplifier generates is comparing an output voltage and the voltage at voltage reference to controlling the output voltage. It generated from the internal oscillator by connecting the timing resistor at frequency pin. At this time, the actual frequency $1 \mathrm{MHz}$ also can be proof. It will produce the PWM output which is a square wave (Figure 12).

\section{Discussion}

The voltage output cannot reach to higher limit cause of the component condition. The simulation and hardware implementation can show that the current is really to control to achieve the output range. The capacitor also can be used at the output and the soft start pin to smoothen the transition. The waveform obtained is not smooth and stable cause of component heat after several times. It may happen cause of noises came from the circuit and can bring losses in the circuit. So it can affect the efficiency of the driver.

\section{CONCLUSION AND RECOMMENDATION}

\section{A. Conclusion}

As conclusion, during the period that has been taken to accomplish this project, many things have been learned and observed. This final year project requires the student to make more effort by himself by managing the progress of this project. Student need to manage the time spent between this project and his study and learn many skills to accomplish this final year project. The skills that have learned are how to do research and do the simulation using LTspice.

In designing a dc-dc converter, a tight output voltage is expected to be the desired result. In order to overcome the problem, a controller scheme is needed and for this project purposes, current mode control scheme is been chosen.

LTspice software is used widely in investigating and design project for boost converter in order to determine if the circuit meets the design criteria.

Since the simulation of Current Mode Control for Boost Converter well done by using LTspice during this project 1 , the implementation of the prototype hardware is done where the expected rout come and result from this project is to get the output voltage by using the boost converter from LTspice simulation and hardware has completed.

\section{B. Recommendation}

For the future improvement, the efficiency of the High Power LED Driver can be increase by perfectly selecting the component knowledge. The right component value also hardly to find and the nearly value is selected. It will affect the result and can decrease the efficiency of LED. In design PCB, the double layer PCB board can be used to minimize the size of driver. Applying the heat sink to the board and the LED string is good to absorb the heat when driver is operating in long time.

\section{ACKNOWLEDGMENT}

The preferred spelling of the word "acknowledgment" in America is without an "e" after the "g." Try to avoid the stilted expression, "One of us (R. B. G.) thanks ..." Instead, try "R.B.G. thanks ..." Put sponsor acknowledgments in the unnumbered footnotes on the first page.

\section{REFERENCES}

[1] Pakpoom Chansri, Nongnuch Noicharoen And Kritsada Phetphoi. "A High Power LED Driver With Class D ZVS Series Resonant Converter". International Conference On Electrical, Control And Computer Engineering. Pahang, Malaysia.June 21-22, 2011

[2] Tom Ribarich. "LED professional Review". Jan/Feb 2009 www.led-professional.com

[3] Mohamad Fakhrudin Sulaiman Mustahim "High-Power LED Driver". Universiti Malaysia Pahang. 2012

[4] A.Hakimi "Low-Power LED Driver". Universiti Malaysia Pahang. 2012

[5] LU Jiaying and WU Xiaobo, "A Novel Multiple Modes PWM Controller for LEDs",Zhejiang University, 2009.

[6] D. W. Hart, "Introduction To Power Electronics", Prentice Hall International

[7] Bengt Johansson "Improved Models for DC-DC Converters" Lund University, Department of Industrial Electrical Engineering and Automation.

[8] Dr. Ray Ridley, “A More Accurate Current-Mode Control Mode”, Ridley Engineering, Inc. 